\title{
THE GEOMETRY OF THE PROXIMAL FEMUR
}

\author{
Zoltán Csernátony, Sándor Manó, László Kiss \\ Department of Orthopaedic Surgery, Medical and Health Science Center, \\ University of Debrecen \\ csz@med.unideb.hu
}

\begin{abstract}
The authors performed radiological and morphological examinations on 86 femurs from fresh cadavers, and present their results to aid the planning of companies manufacturing hip endoprosthesis.
\end{abstract}

Keywords: geometry, femur, Singh index, Barnett-Nordin index

\section{Introduction}

Total hip replacement began its conquest with the low friction arthroplasty principle and implant developed in 1961 by Sir John Charnley. From then on orthopedic surgery, besides numerous other beneficial surgeries, gave such an advantageous solution to patients suffering from hip pain that the prestige of the specialty was greatly increased. It is presently estimated that there are about 3-4.5 million patients benefitting from total hip replacement yearly. In the past 50 years, various implants appeared on the market. During this half century, there were enormous developments in metallurgy and in the chemical industry especially in plastics, material, and machinery, not to mention the advances in surgery itself. Nowadays many basic concepts are used in replacement surgery thus patients are operated along similar trends worldwide. At the same time, the further development of prosthetic replacement has not ended.

About two decades ago, industrial technology offered a new opportunity with the manufacture of custom made prostheses. For a few years, the specialty was unable to come to terms with what the future will bring. The problem was soon answered. The solution was to use off-the-shelf prostheses in routine cases, thereby shaping the patient to the implant and not shaping the implant to the patient. For this the size differential between the implants became more refined. However, it must be kept in mind that within certain limits the geometry can vary in different populations.

\section{Methods and Materials}

In our present work, we performed direct and radiological examination of 86 proximal femurs from 43 cadavers from Hajdú-Bihar County. The femurs were removed with the permission of the University of Debrecen, Medical Health and Science Center Regional and Institutional Ethics Committee. The deceased were all Caucasian. The measurement points and characteristics are shown in Figure 1. The Singh ${ }^{5}$ and Barnett-Nordin indices $^{1,3}$ were also measured, the latter one in an extended form, 10, 20 and 30 centimeters below the lesser trochanter in both the AP and lateral views ${ }^{2}$.

In Figure 1., for the sake of simplicity, the calculation method used to calculate the index 20 centimeters from the tip of the greater 


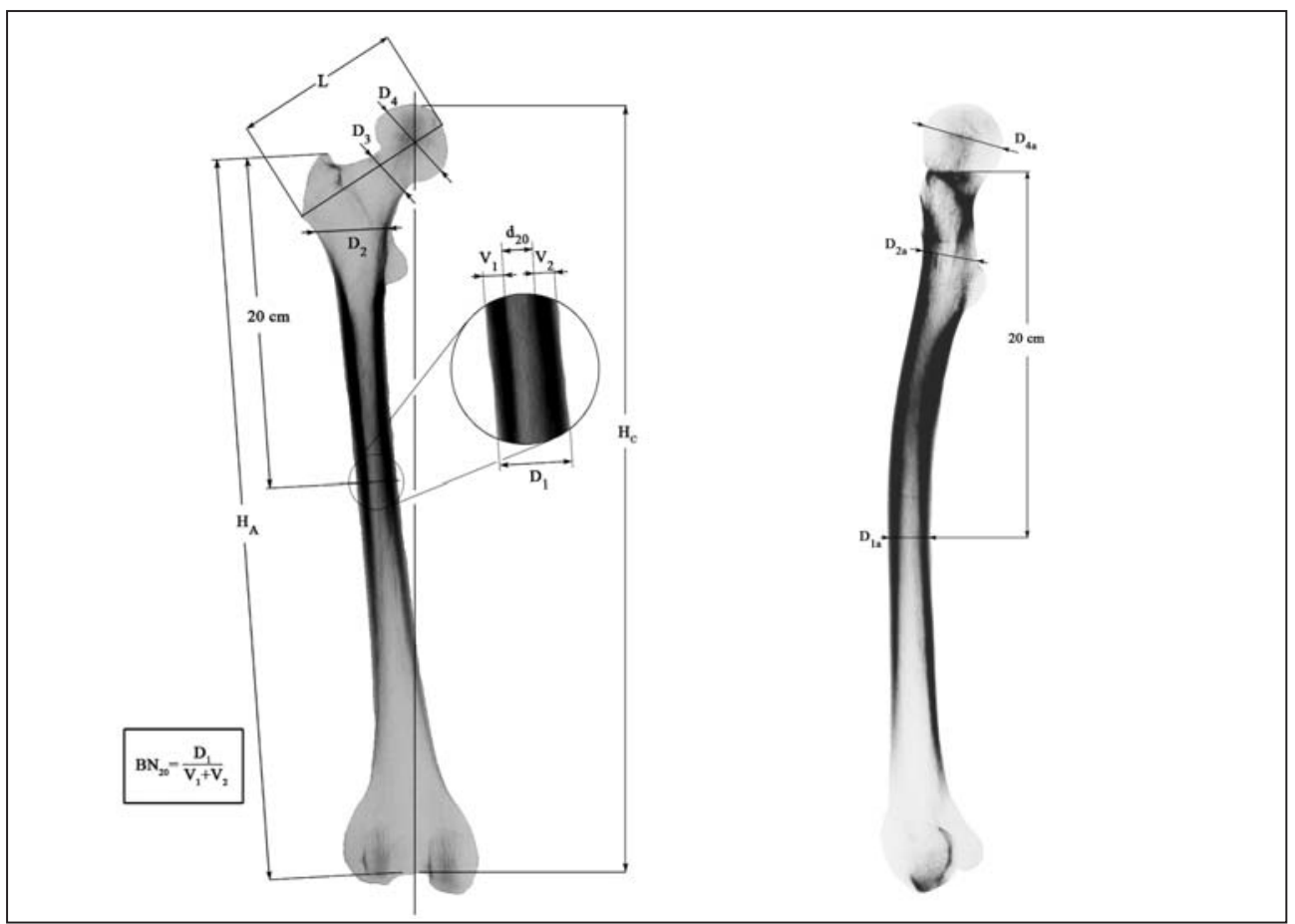

Figure 1. The measurement points and characteristics with the Barnett-Nordin index

trochanter $\left(\mathrm{BN}_{20}\right)$ is demonstrated. We divided the diameter of the femur with the sum of the thickness of the outer and inner cortical bone.
The Singh index is a less exact, but practically useful radiological method to determine the level of osteoporosis which is based on the progressive disappearance of the bone scaffolds in the proximal femur (Figure 2).
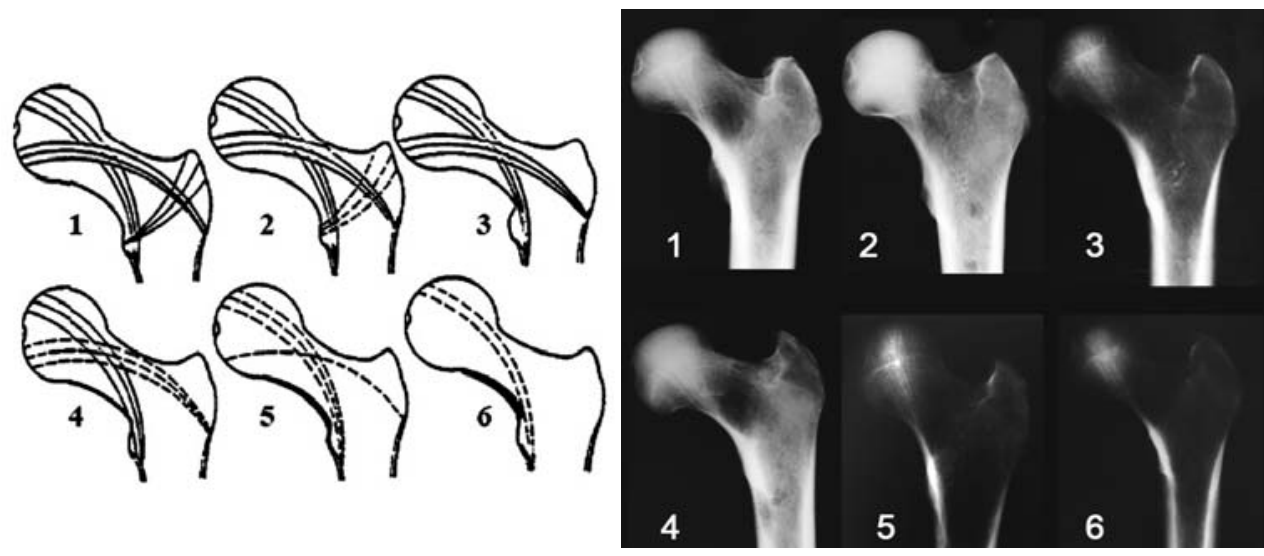

Figure 2. The interpretation of the Singh index 


\section{Results}

The measurement data are shown in Table I.

\begin{tabular}{|c|c|c|c|c|c|c|c|c|c|c|c|c|c|c|c|}
\hline No & $\begin{array}{l}\text { Age } \\
\text { (year) }\end{array}$ & $\begin{array}{c}\mathrm{L} \\
(\mathrm{mm})\end{array}$ & $\begin{array}{c}\mathrm{D}_{1} \\
(\mathrm{~mm})\end{array}$ & $\begin{array}{c}\mathrm{D}_{1 \mathrm{a}} \\
(\mathrm{mm})\end{array}$ & $\begin{array}{c}\mathrm{D}_{2} \\
(\mathrm{~mm})\end{array}$ & $\begin{array}{c}\mathrm{D}_{2 \mathrm{a}} \\
(\mathrm{mm})\end{array}$ & $\begin{array}{c}\mathrm{D}_{3} \\
(\mathrm{~mm})\end{array}$ & $\begin{array}{c}\mathrm{D}_{4} \\
(\mathrm{~mm})\end{array}$ & $\begin{array}{c}\mathrm{D}_{4 \mathrm{a}} \\
(\mathrm{mm})\end{array}$ & $\begin{array}{c}\mathrm{d}_{10} \\
(\mathrm{~mm})\end{array}$ & $\begin{array}{c}\mathrm{d}_{20} \\
(\mathrm{~mm})\end{array}$ & $\mathrm{S}$ & $\mathrm{BN}_{10}$ & $\mathrm{BN}_{20}$ & $\mathrm{BN}_{30}$ \\
\hline 1. & 49 & 116 & 34 & 30 & 41 & 44 & 37 & 57 & 59 & 25 & 14 & 6 & 0.39 & 0.59 & 0.39 \\
\hline 2. & 49 & 117 & 38 & 31 & 45 & 43 & 38 & 57 & 59 & 19 & 18 & 6 & 0.45 & 0.57 & 0.37 \\
\hline 3. & 73 & 95 & 24 & 27 & 39 & 30 & 30 & 44 & 45 & 15 & 10 & 4 & 0.50 & 0.58 & 0.26 \\
\hline 4. & 73 & 93 & 25 & 28 & 37 & 30 & 32 & 44 & 45 & 17 & 19 & 5 & 0.61 & 0.56 & 0.37 \\
\hline 5. & 86 & 98 & 31 & 20 & 40 & 34 & 31 & 46 & 48 & 23 & 12 & 4 & 0.34 & 0.61 & 0.27 \\
\hline 6. & 86 & 96 & 32 & 22 & 42 & 37 & 32 & 47 & 48 & 19 & 15 & 4 & 0.44 & 0.53 & 0.33 \\
\hline 7. & 81 & 95 & 24 & 23 & 39 & 32 & 31 & 48 & 48 & 12 & 12 & 5 & 0.54 & 0.58 & 0.35 \\
\hline 8. & 81 & 93 & 23 & 23 & 41 & 31 & 30 & 46 & 38 & 11 & 10 & 3 & 0.58 & 0.57 & 0.22 \\
\hline 9. & 83 & 100 & 26 & 27 & 49 & 38 & 37 & 53 & 55 & 20 & 11 & 5 & 0.41 & 0.58 & 0.14 \\
\hline 10. & 83 & 98 & 26 & 27 & 46 & 42 & 37 & 54 & 54 & 24 & 15 & 5 & 0.33 & 0.42 & 0.11 \\
\hline 11. & 83 & 106 & 30 & 30 & 47 & 48 & 37 & 55 & 53 & 21 & 15 & 4 & 0.42 & 0.50 & 0.28 \\
\hline 12. & 83 & 103 & 30 & 29 & 48 & 47 & 34 & 53 & 54 & 20 & 15 & 5 & 0.41 & 0.50 & 0.24 \\
\hline 13. & 46 & 101 & 28 & 25 & 43 & 34 & 27 & 46 & 47 & 20 & 13 & 4 & 0.39 & 0.54 & 0.37 \\
\hline 14. & 46 & 101 & 28 & 24 & 44 & 35 & 28 & 46 & 47 & 23 & 9 & 4 & 0.49 & 0.61 & 0.30 \\
\hline 15. & 82 & 110 & 33 & 32 & 52 & 42 & 39 & 53 & 56 & 27 & 17 & 2 & 0.36 & 0.49 & 0.20 \\
\hline 16. & 82 & 113 & 32 & 34 & 52 & 46 & 38 & 54 & 56 & 24 & 16 & 2 & 0.39 & 0.50 & 0.19 \\
\hline 17. & 55 & 104 & 31 & 31 & 43 & 40 & 37 & 49 & 52 & 19 & 15 & 4 & 0.47 & 0.52 & 0.27 \\
\hline 18. & 55 & 101 & 31 & 32 & 47 & 38 & 34 & 50 & 50 & 20 & 13 & 3 & 0.47 & 0.58 & 0.26 \\
\hline 19. & 41 & 103 & 35 & 30 & 42 & 37 & 31 & 47 & 49 & 13 & 8 & 4 & 0.54 & 0.68 & 0.30 \\
\hline 20. & 41 & 102 & 24 & 30 & 39 & 36 & 31 & 48 & 49 & 13 & 7 & 4 & 0.54 & 0.63 & 0.29 \\
\hline 21. & 60 & 102 & 29 & 26 & 44 & 41 & 33 & 50 & 51 & 20 & 16 & 4 & 0.39 & 0.45 & 0.15 \\
\hline 22. & 60 & 100 & 27 & 26 & 44 & 41 & 34 & 51 & 53 & 21 & 16 & 4 & 0.36 & 0.41 & 0.13 \\
\hline 23. & 78 & 102 & 29 & 28 & 43 & 38 & 32 & 49 & 50 & 17 & 13 & 5 & 0.46 & 0.55 & 0.25 \\
\hline 24. & 78 & 100 & 28 & 29 & 43 & 37 & 33 & 48 & 52 & 19 & 12 & 5 & 0.42 & 0.57 & 0.36 \\
\hline 25. & & 89 & 29 & 24 & 43 & 37 & 34 & - & - & 16 & 11 & 5 & 0.48 & 0.62 & 0.22 \\
\hline 26. & & 90 & 31 & 25 & 40 & 38 & 32 & 45 & 45 & 17 & 14 & 5 & 0.50 & 0.55 & 0.23 \\
\hline 27. & 61 & 113 & 28 & 28 & 45 & 30 & 34 & 52 & 55 & 17 & 9 & 4 & 0.50 & 0.68 & 0.35 \\
\hline 28. & 61 & 110 & 29 & 30 & 44 & 36 & 33 & 52 & 54 & 18 & 10 & 4 & 0.47 & 0.66 & 0.28 \\
\hline 29. & 72 & 106 & 35 & 25 & 47 & 39 & 33 & 53 & 53 & 18 & 13 & 4 & 0.51 & 0.63 & 0.30 \\
\hline 30. & 72 & 102 & 32 & 26 & 47 & 40 & 30 & 50 & 51 & 20 & 13 & 4 & 0.46 & 0.59 & 0.28 \\
\hline 31. & 64 & 87 & 25 & 26 & 38 & 32 & 29 & 44 & 44 & 16 & 10 & 2 & 0.39 & 0.60 & 0.13 \\
\hline 32. & 64 & 85 & 27 & 25 & 40 & 34 & 30 & 43 & 43 & 15 & 12 & 1 & 0.44 & 0.56 & 0.16 \\
\hline 33. & 46 & 89 & 24 & 24 & 38 & 28 & 28 & 43 & 44 & 13 & 11 & 3 & 0.54 & 0.54 & 0.13 \\
\hline 34. & 46 & 89 & 25 & 26 & 38 & 28 & 29 & 42 & 43 & 14 & 12 & 3 & 0.50 & 0.52 & 0.16 \\
\hline 35. & 71 & 106 & 30 & 26 & 44 & 35 & 31 & 49 & 50 & 22 & 12 & 4 & 0.37 & 0.60 & 0.30 \\
\hline 36. & 71 & 108 & 30 & 23 & 42 & 34 & 34 & 50 & 50 & 18 & 13 & 4 & 0.51 & 0.57 & 0.41 \\
\hline 37. & 53 & 105 & 34 & 28 & 50 & 40 & 45 & 53 & 53 & 18 & 11 & 6 & 0.50 & 0.57 & 0.42 \\
\hline 38. & 53 & 104 & 34 & 27 & 49 & 33 & 35 & 53 & 53 & 18 & 14 & 5 & 0.49 & 0.59 & 0.36 \\
\hline 39. & 42 & 106 & 33 & 30 & 47 & 40 & 35 & 54 & 55 & 24 & 18 & 4 & 0.35 & 0.46 & 0.45 \\
\hline 40. & 42 & 103 & 33 & 29 & 48 & 39 & 34 & 53 & 54 & 25 & 20 & 4 & 0.34 & 0.39 & 0.40 \\
\hline 41. & 74 & 107 & 28 & 28 & 48 & 40 & 35 & 50 & 53 & 15 & 11 & 4 & 0.53 & 0.61 & 0.32 \\
\hline 42. & 74 & 106 & 28 & 29 & 48 & 42 & 34 & 51 & 52 & 15 & 11 & 4 & 0.53 & 0.61 & 0.26 \\
\hline 43. & 42 & 101 & 29 & 29 & 46 & 35 & 37 & 49 & 51 & 18 & 14 & 6 & 0.46 & 0.52 & 0.27 \\
\hline 44. & 42 & 98 & 28 & 29 & 48 & 37 & 34 & 49 & 51 & 20 & 13 & 6 & 0.38 & 0.54 & 0.29 \\
\hline 45. & 69 & 96 & 29 & 26 & 41 & 37 & 27 & 44 & 45 & 23 & 17 & 4 & 0.30 & 0.41 & 0.32 \\
\hline 46. & 69 & 96 & 28 & 28 & 41 & 38 & 26 & 44 & 45 & 24 & 15 & 4 & 0.29 & 0.46 & 0.29 \\
\hline 47. & 88 & 88 & 25 & 29 & 40 & 37 & 28 & 42 & 44 & 18 & 13 & 4 & 0.36 & 0.46 & 0.13 \\
\hline 48. & 88 & 88 & 25 & 27 & 38 & 40 & 30 & 42 & 42 & 21 & 14 & 4 & 0.30 & 0.44 & 0.13 \\
\hline 49. & 62 & 104 & 27 & 26 & 47 & 38 & 29 & 56 & 58 & 18 & 12 & 5 & 0.44 & 0.56 & 0.18 \\
\hline 50. & 62 & 104 & 28 & 26 & 45 & 40 & 30 & 55 & 55 & 18 & 12 & 4 & 0.46 & 0.57 & 0.17 \\
\hline 51. & 83 & 110 & 30 & 29 & 48 & 37 & - & - & - & 20 & 10 & 5 & 0.46 & 0.67 & 0.36 \\
\hline 52. & 83 & 109 & 27 & 28 & 42 & 43 & 39 & 56 & 60 & 22 & 12 & 5 & 0.37 & 0.56 & 0.29 \\
\hline 53. & 69 & 97 & 30 & 26 & 47 & 43 & - & - & - & 19 & 15 & 3 & 0.40 & 0.50 & 0.31 \\
\hline 54. & 69 & 100 & 28 & 27 & 45 & 38 & 35 & 49 & 49 & 22 & 14 & 5 & 0.34 & 0.50 & 0.29 \\
\hline
\end{tabular}




\begin{tabular}{|c|c|c|c|c|c|c|c|c|c|c|c|c|c|c|c|}
\hline No & $\begin{array}{l}\text { Age } \\
\text { (year) }\end{array}$ & $\begin{array}{c}\mathrm{L} \\
(\mathrm{mm})\end{array}$ & $\begin{array}{c}\mathrm{D}_{1} \\
(\mathrm{~mm})\end{array}$ & $\begin{array}{c}\mathrm{D}_{1 \mathrm{a}} \\
(\mathrm{mm})\end{array}$ & $\begin{array}{c}\mathrm{D}_{2} \\
(\mathrm{~mm})\end{array}$ & $\begin{array}{c}\mathrm{D}_{2 \mathrm{a}} \\
(\mathrm{mm})\end{array}$ & $\begin{array}{c}\mathrm{D}_{3} \\
(\mathrm{~mm})\end{array}$ & $\begin{array}{c}\mathrm{D}_{4} \\
(\mathrm{~mm})\end{array}$ & $\begin{array}{c}\mathrm{D}_{4 \mathrm{a}} \\
(\mathrm{mm})\end{array}$ & $\begin{array}{c}\mathrm{d}_{10} \\
(\mathrm{~mm})\end{array}$ & $\begin{array}{c}\mathrm{d}_{20} \\
(\mathrm{~mm})\end{array}$ & $S$ & $\mathrm{BN}_{10}$ & $\mathrm{BN}_{20}$ & $\mathrm{BN}_{30}$ \\
\hline 55. & 49 & 109 & 31 & 29 & 57 & 40 & 38 & 58 & 57 & 18 & 11 & 4 & 0.41 & 0.65 & 0.18 \\
\hline 56. & 49 & 108 & 30 & 28 & 52 & 42 & 34 & 57 & 56 & 20 & 15 & 4 & 0.38 & 0.50 & 0.19 \\
\hline 57. & 77 & 105 & 27 & 26 & 45 & 37 & 32 & 52 & 54 & 15 & $\overline{9}$ & 4 & 0.55 & 0.67 & 0.25 \\
\hline 58. & 77 & 107 & 27 & 26 & 46 & 36 & 31 & 53 & 54 & 16 & 8 & 4 & 0.48 & 0.70 & 0.24 \\
\hline 59. & 68 & - & 26 & 21 & 41 & 33 & 29 & 43 & 44 & 13 & 11 & 4 & 0.55 & 0.58 & 0.17 \\
\hline 60. & 68 & 92 & 27 & 20 & 40 & 30 & 30 & 43 & 44 & 14 & 12 & 4 & 0.46 & 0.56 & 0.20 \\
\hline 61. & 85 & 93 & 26 & 28 & 44 & 44 & 31 & 47 & 48 & 18 & 10 & 4 & 0.42 & 0.62 & 0.31 \\
\hline 62. & 85 & 95 & 26 & 32 & 43 & 40 & 34 & 49 & 48 & 19 & 10 & 4 & 0.37 & 0.62 & 0.43 \\
\hline 63. & 70 & 105 & 28 & 27 & 43 & 39 & 33 & 50 & 52 & 23 & 12 & 4 & 0.30 & 0.57 & 0.30 \\
\hline 64. & 70 & 107 & 30 & 27 & 46 & 42 & 33 & 50 & 52 & 22 & 12 & 4 & 0.33 & 0.60 & 0.33 \\
\hline 65. & 78 & 86 & 23 & 24 & 40 & 37 & 31 & 44 & 44 & 22 & 17 & 4 & 0.21 & 0.26 & 0.18 \\
\hline 66. & 78 & 89 & 26 & 28 & 39 & 34 & 32 & 44 & 46 & 22 & 16 & 4 & 0.31 & 0.39 & 0.21 \\
\hline 67. & 56 & 96 & 30 & 26 & 40 & 36 & 31 & 51 & 51 & 20 & 14 & 4 & 0.43 & 0.53 & 0.32 \\
\hline 68. & 56 & 96 & 29 & 26 & 42 & 35 & 30 & 51 & 52 & 17 & 11 & 4 & 0.49 & 0.62 & 0.32 \\
\hline 69. & 72 & 103 & 27 & 27 & 45 & 36 & 32 & 50 & 52 & 21 & 12 & $\overline{4}$ & 0.35 & 0.56 & 0.36 \\
\hline 70. & 72 & 103 & 27 & 29 & 44 & 37 & 32 & 51 & 52 & 19 & 12 & 4 & 0.42 & 0.56 & 0.36 \\
\hline 71. & 46 & 107 & 27 & 30 & 46 & 38 & 35 & 55 & 56 & 21 & 13 & 2 & 0.38 & 0.52 & 0.21 \\
\hline 72. & 46 & 105 & 29 & 30 & 50 & 40 & 37 & 55 & 56 & 24 & 15 & 2 & 0.31 & 0.48 & 0.27 \\
\hline 73. & 82 & 109 & 28 & 28 & 42 & 40 & 35 & 52 & 51 & 16 & 13 & 5 & 0.52 & 0.54 & 0.22 \\
\hline 74. & 82 & 103 & 28 & 27 & 48 & 38 & 36 & 50 & 51 & 17 & 12 & 5 & 0.49 & 0.57 & 0.25 \\
\hline 75. & 39 & 116 & 26 & 31 & 46 & 38 & 33 & 58 & 58 & 19 & 12 & 4 & 0.44 & 0.54 & 0.28 \\
\hline 76. & 39 & 114 & 27 & 33 & 48 & 39 & 34 & 58 & 58 & 21 & 12 & 4 & 0.40 & 0.56 & 0.31 \\
\hline 77. & 55 & 114 & 31 & 31 & 46 & 42 & 36 & 54 & 56 & 21 & 16 & 5 & 0.42 & 0.48 & 0.24 \\
\hline 78. & 55 & 108 & 30 & - & 47 & - & 35 & 54 & - & 19 & 10 & 5 & 0.49 & 0.67 & 0.28 \\
\hline 79. & 76 & 95 & 25 & 24 & 42 & 32 & 28 & 46 & 47 & 14 & 10 & 4 & 0.48 & 0.60 & 0.17 \\
\hline 80. & 76 & 97 & 23 & 23 & 40 & 33 & 28 & 44 & 46 & 14 & 10 & 4 & 0.48 & 0.57 & 0.18 \\
\hline 81. & 36 & 94 & 25 & 30 & 48 & 40 & 34 & 49 & 51 & 18 & $\overline{9}$ & 3 & 0.42 & 0.64 & 0.26 \\
\hline 82. & 36 & 95 & 26 & 28 & 44 & 42 & 33 & 49 & 49 & 18 & 10 & 2 & 0.44 & 0.62 & 0.25 \\
\hline 83. & 80 & 88 & 27 & 29 & 40 & 36 & 29 & 44 & 46 & 18 & 12 & 3 & 0.36 & 0.56 & 0.25 \\
\hline 84. & 80 & 88 & 28 & 28 & 41 & 37 & 33 & 45 & 46 & 20 & 13 & 4 & 0.33 & 0.54 & 0.24 \\
\hline 85. & 76 & 104 & 27 & 30 & 47 & 41 & 34 & 53 & 57 & 21 & 10 & 5 & 0.38 & 0.63 & 0.36 \\
\hline 86. & 76 & 106 & 26 & 28 & 44 & 43 & 32 & 62 & 53 & 21 & 10 & 2 & 0.36 & 0.62 & 0.29 \\
\hline
\end{tabular}

Key

\section{male female}

$\mathrm{K}$ age (year)

L femoral neck-head length (mm)

$\mathrm{D}_{1}$ the outer diameter of the femur in the frontal plane $20 \mathrm{~cm}$ from the tip of the greater trochanter $(\mathrm{mm})$

$\mathrm{D}_{1 \mathrm{a}}$ the outer diameter of the femur in the sagittal plane $20 \mathrm{~cm}$ from the tip of the greater trochanter $(\mathrm{mm})$

$\mathrm{D}_{2}$ the outer diameter of the femur in the frontal plane at the top of the lesser trochanter $(\mathrm{mm})$

$\mathrm{D}_{2 \mathrm{a}}$ the outer diameter of the femur in the sagittal plane at the top of the lesser trochanter $(\mathrm{mm})$

$\mathrm{D}_{3}$ the diameter of the femoral neck in the frontal plane $(\mathrm{mm})$

$\mathrm{D}_{4}$ the diameter of the femoral head in the frontal plane $(\mathrm{mm})$

$\mathrm{D}_{4 a}$ the diameter of the femoral head in the sagittal plane $(\mathrm{mm})$

$\mathrm{d}_{10}$ the diameter of the femoral canal $10 \mathrm{~cm}$ from the greater trochanter $(\mathrm{mm})$

$\mathrm{d}_{20}$ the diameter of the femoral canal $20 \mathrm{~cm}$ from the greater trochanter $(\mathrm{mm})$

$\mathrm{S}$ Singh index

$\mathrm{BN}_{10}$ Barnett-Nordin index (10 cm from the tip of the greater trochanter)

$\mathrm{BN}_{20}$ Barnett-Nordin index (20 cm from the tip of the greater trochanter)

$\mathrm{BN}_{30}$ Barnett-Nordin index $(30 \mathrm{~cm}$ from the tip of the greater trochanter)

$\mathrm{V}_{1}$ the lateral thickness of the cortical bone

$\mathrm{V}_{2}$ the medial thickness of the cortical bone

Table I. The geometrical data of the femur measurements 
The higher the value of the Barnett-Nordin index the wider the medullary canal. The index has the lowest value at 20 centimeters from the tip of the greater trochanter when determined at 10, 20, and 30 centimeters; the reason for this can be explained on the lateral view of the femur, because at this level the posterior cortex is thickened in the concavity of the physiological anterior bowing of the femur. At 30 centimeters from the tip of the greater trochanter we are below the narrow- ing of the medullar canal of the femur, where the canal is wider compared to the cortical bone (Figure 1 and Diagram 1).

The Singh index shows a Gaussian distribution (Diagram 2).

The difference in the frontal and sagittal diameter of the femoral head has a greater distribution with increased age. The highest values were observed at around 80 years of

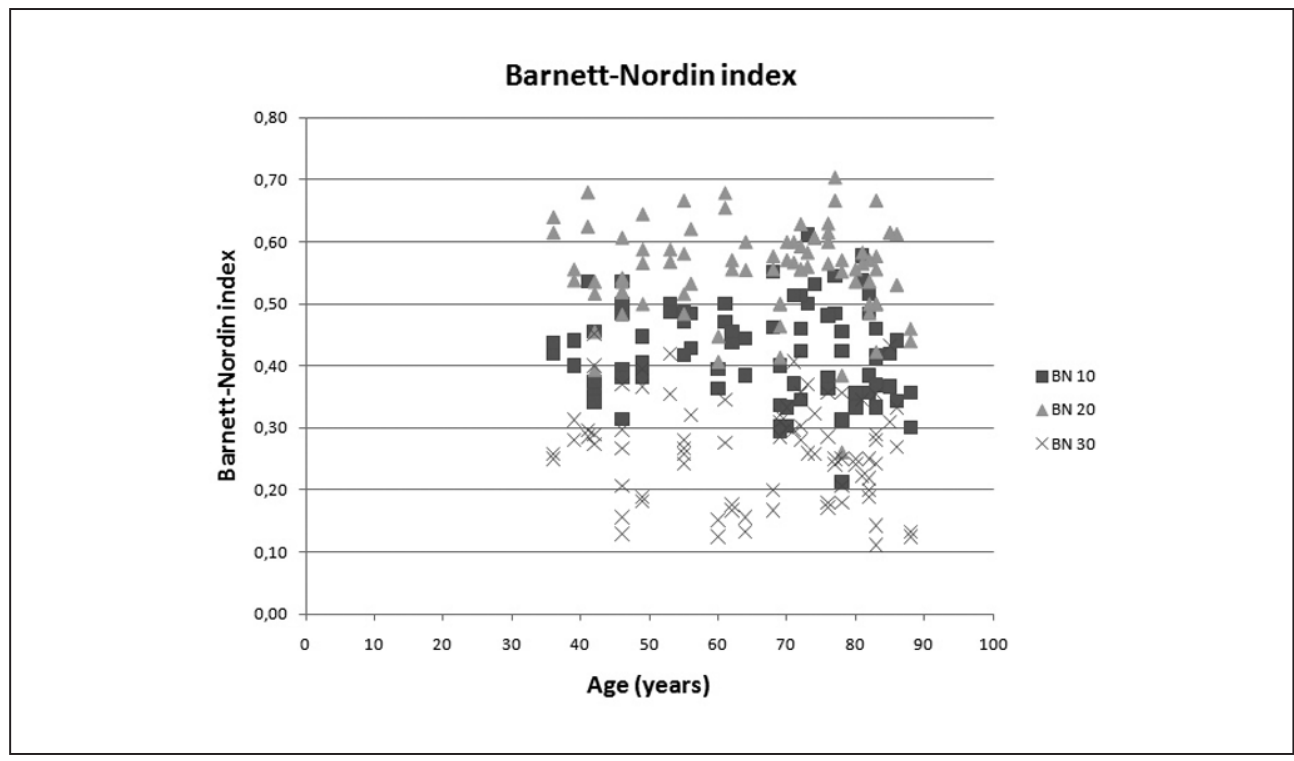

Diagram 1. The relation between the Barnett-Nordin index and age

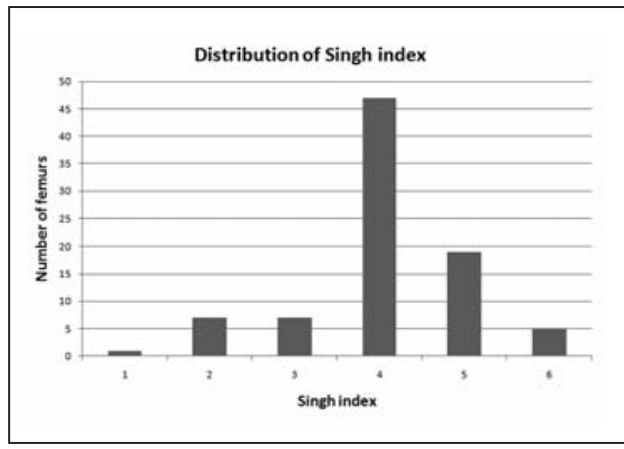

Diagram 2. The distribution of the Singh index

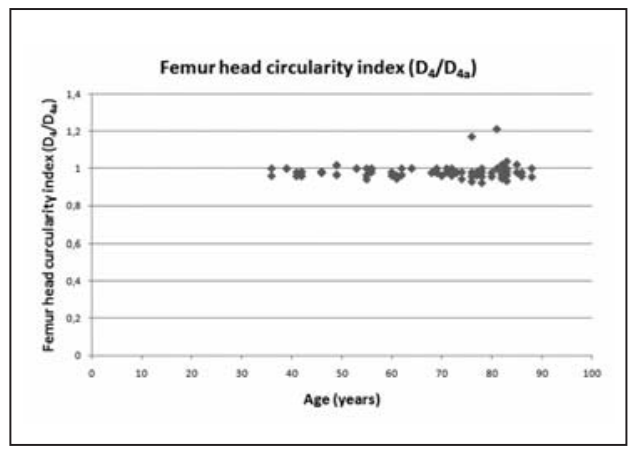

Diagram 3. The relation between the ratio of the frontal and sagittal diameter of the femur and age 
age. This can be explained by the deformities caused by arthrosis and osteophytes usually present by this age (Diagram 3).

\section{Discussion}

One of the key steps in successful total hip replacement is the selection of the right size of femoral stem from a surgical point of view, and the geometry of the femoral stem from the manufacturer's perspective. Data bases that can provide help with this are limited in the literature ${ }^{4}$. It is typical that most manufactured femoral stems possess the same geometry throughout all available sizes; for this reason it would be interesting to compare population statistics during the planning phase. We hoped to assist this research and development phase with our present work.
We performed femoral head measurements, because the size of the bony acetabulum can be estimated from this information, and we find that this is also important during prosthesis manufacturing.

Nowadays hip replacement is not exclusively a surgical technique for the older age group, due to the expansion of the indication criteria more and more middle-aged patients, and in some cases even very young individuals require surgery.

The decision to use cemented or non-cemented prosthesis greatly depends on geometrical changes seen in osteoporosis, and the type of prosthesis used depends ideally on the geometry of the femur.

\section{REFERENCES}

1. Barnett E, Nordin BEC. I. The Clinical and radiological problem of thin bones. The British journal of radiology 1961;407:683-92.

2. Csernátony Z. Diplôme d'Etudes Approfondies (DEA) en Biomécanique et Biomatériaux. Ecole Nationale Superieure d' Arts et Metiers, Paris; 1993.

3. Grampp S, Steiner E, Imhof H. Radiological diagnosis of osteoporosis. European Radiology. 1997(Suppl 2):11-9.
4. Józsa L. A proximális femur-vég geometriája. Magyar Traumatológia, Ortopédia, Kézsebészet, Plasztikai Sebészet 1999;42:250-6.

5. Koot VCM, Kesselaer SMMJ, Clevers GJ, de Hooge P, Weits T, van deer Werken Chr. Evaluation of the Singh index for measuring osteoporosis. J Bone Joint Surg Br 1996;78B:831-4.

\section{Zoltán Csernátony}

Department of Orthopaedic Surgery, Medical and Health Science Center, University of Debrecen H-4032 Debrecen, Nagyerdei krt. 98.

Tel.: (+36) 52 255-815 